Decision Making in Manufacturing and Services

VOL. $13 \bullet 2019 \bullet$ No. 1-2 • PP. 37-51

\title{
Preferable Ways of Decision-Making in IT Teams
}

\author{
Beata Krawczyk-Bryłka*, Henryk Krawczyk**
}

\begin{abstract}
Software development team collaboration requires various decisions regarding essential aspects of a project's progress. General and particular decision-making models are considered, and their main aspects such as team types, problem solving categories, and decision-making ways are analyzed. The research concerns representative groups of IT specialists and their preferences in decision-making are investigated. Four possible cases were tested: hierarchical choice (by leader) team members' choice (team consensus or voting) and external expert impact. It allows one to show some differences in the behaviors of both traditional and virtual teams.
\end{abstract}

Keywords: software development, IT teams, virtual collaboration, cloud computing, decision-making

Mathematics Subject Classification: 90B50, 68R99, 68U35

Submitted: May 29, 2018

Revised: August 09, 2019

(C) 2019 Authors. This is an open access publication, which can be used, distributed and reproduced in any medium according to the Creative Commons CC-BY 4.0 License. License requiring that the original work has been properly cited.

\section{INTRODUCTION}

The majority of software design problems are solved either by teams working on developing applications or external experts. We can distinguish two kinds of such teams. In general, a traditional team is a group of people linked by a common purpose and where its members have complementary skills. This allows them to maximize their strengths and minimize their weaknesses in order to improve their performance, and to solve their problems or to finalize their tasks successfully. In the case of IT teams, the main task is the software development of specified applications. IT teams can work in a traditional environment or in a virtual one. A virtual team is also a group of individuals who work together, their tasks are interdependent, inseparable, and leading to a common goal, but they are geographically dispersed and their communication depends on ICT platforms (Dávideková, Hvorecký, 2017). However, it is not easy to evaluate how virtual a team is. In general, there are three predominant factors that contribute to virtuality. The first one is the utilization level of IT technology as

* Gdansk University of Technology, Faculty of Management and Economics, Gdansk, Poland, e-mail: beabrylk@pg.edu.pl

** Gdansk University of Technology, Faculty of Telecommunications and Informatics, Gdansk, Poland, e-mail: hkrawk@pg.edu.pl 
mentioned above. The second one is the distance between team member's, in terms of geographical dispersion and, as a result, in time zones. The third one is organizational and concerns the cultural diversity which affects team members' relationships and team output. Below, we consider two such kinds of software design teams: traditional and virtual ones.

Traditional, or so-called face to face teams (f2f), and virtual (v) ones, are still under research and examination. It is a known fact that virtual teams generate more ideas compared to traditional ones. However, virtual teams require a longer amount of time to reach decisions. When comparing the performance of $\mathrm{f} 2 \mathrm{f}$ teams and $\mathrm{v}$ teams, opinions about them are mixed. Some empirical research shows that real teams are better (Schmidt, 2001), while others have found that virtual teams succeed; and other research confirms that they are at the same level. Progress in communication media (e.g. 3D virtual environments) brings these two kinds of teams closer (Bourgault et al., 2008). We will concentrate only on decision-making processes accompanying the work of such teams. We consider the same decisions, taken in both kinds of teams, and compare them in order to distinguish differences. We cannot analyze why some of them make correct decisions, while other teams reach a wrong decision. There are many causes of this, including: the quality and experience of team members, their leader's skills type, conditions of the working environment, social and surrounding context and current circumstances, existing relations among members or working atmosphere and also organizational and technical support. (Shalloway et al., 2009) During recent decades researchers have found many conditions under which groups make better decisions than individuals (Nemiro et al., 2008). However, in the case of decision-making in virtual teams, many problems are open and need more research. In this paper we limit our considerations to some aspects of f2f teams and v teams, as is shown in Figure 1. Some elements of computing environments, and development platforms, structures of organization and different management strategies are analyzed. The representative IT teams were tested by means of a specially prepared questionnaire, and different methods of making decisions in the above context are analyzed.

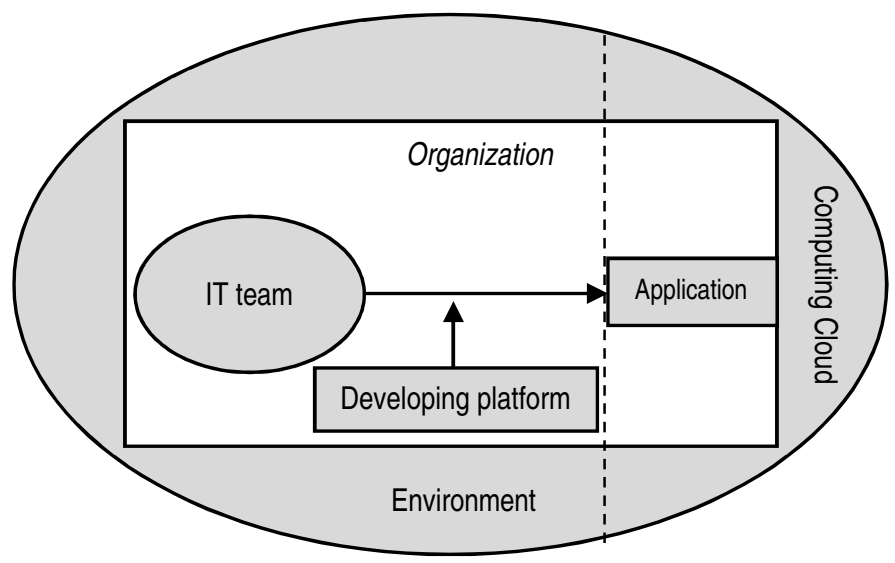

Fig. 1. Software development team environment 
The aim of project management is to achieve all of the assumed project goals with the specified constraints. In care of software development, we distinguish two basic stages of design and implementation: Planning \& Design phase and Implementation \& Improvement one. In the first stage, the aim of the project is defined, and how to achieve it is determined. In the case of software design, after the specification of program requirements, the basic program components are proposed and their main interfaces are determined. In other words, the program architecture is evolved (see Fig. 2a). The second phase describes activities related to project implementation. In such a case, based on the results of the first phase, all of the software components are programmed, tested and improved, until the obtained program satisfies all of the software requirements (see Fig. 2b).
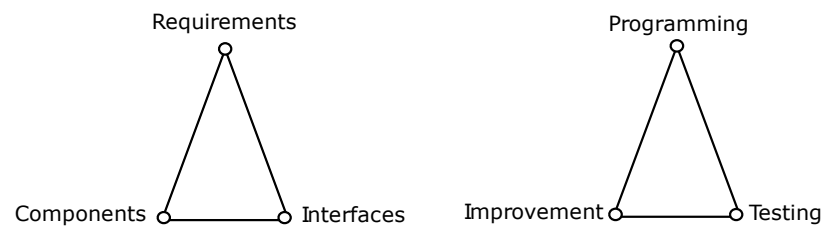

Fig. 2. The software development stages: Planning \& Design (a) and Implementation \& Improvement (b)

Proper selection of the software requirements and software architecture in the first phase of project development significantly impacts on the efficient realization of the second stage. In the literature there are many proposals about how to organize the best conditions for project realization. There are many possibilities to choose suitable development platforms offering design tools and the computing environments for software design, implementation, testing and improvement (Phillips, 2004).

Currently, the most popular technology is cloud computing (Vasan, 2011). It offers various kinds of services assigned to three layers: IaaS (Infrastructure as a Service), PaaS (Platform as a Service) and SaaS (Software as a Service). In such cases two stages of software development can be supported by the first two layers. We can arrange, in comparison to traditional design and implementation platforms, more flexible and much cheaper development possibilities due to cloud computing (Cohen, 2013).

The Planning and Design stage of software development is much more difficult to implement. Therefore, in our further considerations we assume that the best practice and / or well-known principles must be kept in mind during this phase. Moreover, a team (during the work) should be aligned to the business goals, and should consider all changes in real time. One of the well-known development methods is the PRINCE 2 approach, which provides a method for managing projects with a clearly defined waterfall framework (Pollice et al., 2004). Each activity is defined as a process with key inputs and outputs and with goals to be carried out to deliver a project's outcomes. Besides, it provides a platform for the cooperation of all participants of the project, as well as defining their roles and responsibilities. Also, there are some other international standards (e.g. ISO / IEC / IEEE) that present guidance on project development and management. One of the main purposes of development methods is to accelerate product 
delivery and reduce production costs. The opposite solution of software development based on agile principles. In consequence two stages are performed into waterfall approaches two software development phases (see Fig. 2) are separately realized. Most agile development methods break development work into small parts called increments that are planned and implemented in short time frames (e.g. 1-4 weeks). Each product of such an iteration is evaluated and improved, and after acceptance it is integrated with the earlier accepted parts.

The Agile Manifesto highlights four principles of being agile: individuals and interaction over processes and tools, working software over comprehensive documentation, customer collaboration over contract negotiation and responding to change following a plan. Amongst the most popular examples of this methodology are frameworks such as that of Kanban and Scrum (Shalloway et al., 2009). Such methods, in contrast to waterfall models, focus more on producing working software, and less on documentation. Evaluation reports argue that agile software development helps teams to deliver software faster, improves their ability to manage changes suggested by customers, and leads to an increase of team productivity. It seems to be a preferable approach for virtual project teams. We concentrate on IT teams who use cloud computing systems as well as computing, and simultaneously as a development platform. Moreover, they prefer the agile approach to software development. In this paper, different team creation models are considered, and some simplifications are assumed. It allows one to reduce the scope of decision-making analysis and, as a result, to present a favorable way of decision-making in the case of some well-defined problems.

\section{FROM TEAM CREATIVITY TO DECISION-MAKING MODELS}

A team, to do its work professionally should be well-organized, truly engaged in doing the work, and effectively managed. The teamwork process involves a series of interactions, information exchanges, questioning, answering, creating solutions and showing open problems. There are two kinds of such problems: those which are task-oriented, corresponding to actions directly related to the project purposes, and another, called team-oriented, which refer to personal conflicts, unproductive communication, low member motivation, etc. In both situations, the proper decisions should be made in order to eliminate or reduce negative influences on team output. In this paper we focus on task-oriented problems, but the well-known obstacles related to team relations and team atmosphere must not be forgotten. The most important ones are, for example:

- lack of team identity,

- low participation in a team,

- poor communication,

- ineffective team leadership,

- obstructive conflict,

- group thinking,

- absence of creativity,

- ineffective decision-making. 
The above obstacles are typical for traditional teams but can also affect virtual team collaboration. In the case of virtual teams, some other challenges appear, like: potential misunderstandings and misinterpretation caused by non-verbal communication gaps, lower team cohesion and trust, cultural diversity problems, social isolation or difficulties with brain-storming processes (Zofi, 2012).

It is possible to define some pattern actions for IT teams in order to eliminate the above obstacles. First of all, the team creativity processes should be organized properly, and next the best approaches and solutions should be selected and implemented. In other words, a valid model of decision-making should be defined and used consistently.

There are some well-known team creation models, such as Tuckman's model composed of five stages: forming, storming, norming, performing and adjourning, or the Fisher model, containing steps like: orientation, conflict, emergence and reinforcement (Turban et al., 2011). The newly suggested general team creativity model of possible solutions for the identified problems in the Planning \& Design phase is shown in Figure 3. It is assumed that it consists of four main stages called: definition of problem to solve, gathering knowledge about existing similar problems, referring to well-known solutions or preparation of new ones, and elaboration of possible solutions.

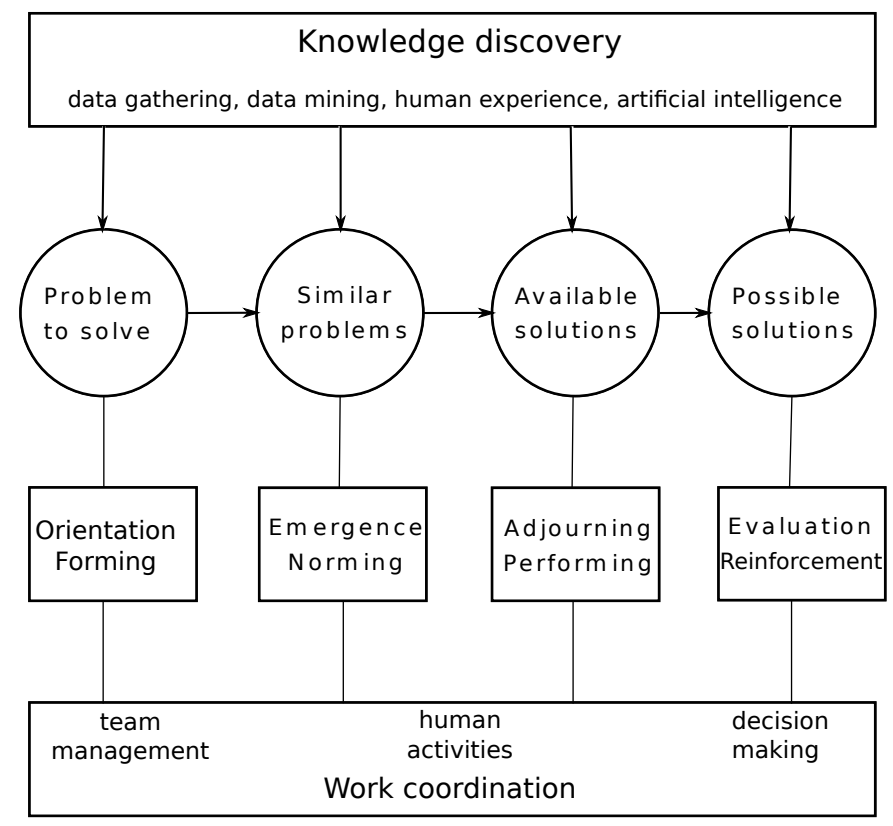

Fig. 3. General team creativity model

First of all, we should identify the problem and recognize the reasons for its occurrence. It is required to evaluate how the team is achieving its results, and to understand what kind of problem it is: task - or team - oriented. In such a stage we can use brain-storming approaches to specify the problem. The next stage refers to data collection about the problem, its context, and available knowledge. In the 
third step, available alternative solutions should be defined and analyzed. In the last step, possible solutions satisfying the assumed limitations can be chosen, based on discovering all available solutions.

To perform all activities determined by the team creativity model properly, extra processes are required. As shown in Figure 3, they belong to two groups: knowledge discovery and work coordination. Some examples of areas of such activities are also shown in Figure 3, by means of upper and lower rectangles. Both of them can be supported by IT oriented systems, such as data mining, artificial intelligence and management and decision supported ones. In each stage of the team creation model, numerous different decisions about the various occurring questions can be taken.

To achieve the goals of the paper, coming from the general model of team creation, and concentrating on available solutions of the considered problems, we can propose the simplified decision-making model shown in Figure 4. The decision-making process concentrates on the selection of the best solution among the available set or subset of solutions, satisfying the step-wisely enhanced "criteria". Therefore, we termed such a model a filter one, where a set of solutions is reduced in each step. Based on the model, it is much easier to characterize the decision-making processes, because we can concentrate on choosing a few solutions from among the available ones. Simplifying, we limit our considerations to the choice of one item from among many existing ones. It allows us to perform an analysis of the ways of decision-making in IT teams. For instance, we want to select the most suitable application architecture from among several possible ones for application implementation.

Let us consider four main ways of decision-making used at each stage of the model.

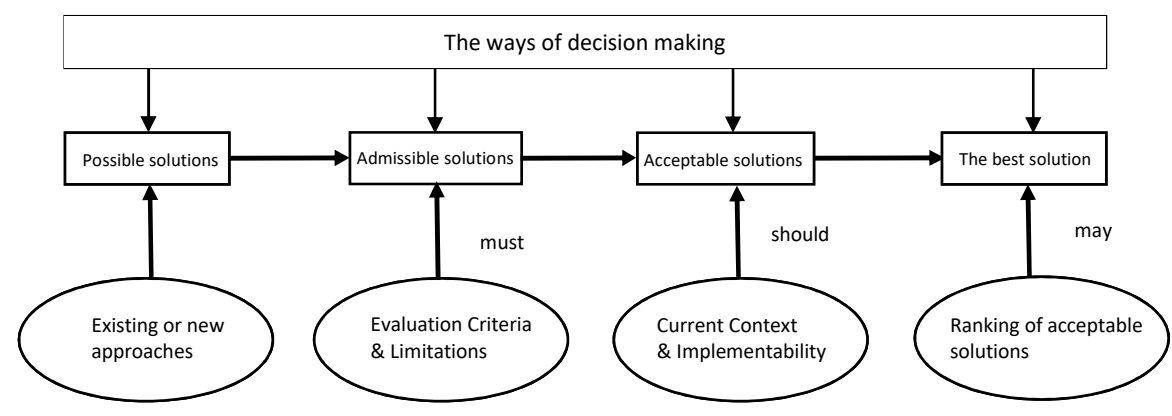

Fig. 4. Filter decision-making model

They determine who, and in what way, decides about the final decision related to the considered problem. Such a decision can be taken:

1) By the leader of the team, who gathers information from members, and uses it to make personal decisions.

2) By consensus, where every member of the team must agree to adopt a proposed decision. If it is not possible, new alternatives are formulated and presented for evaluation. 
3) By voting, where members of the team discuss the decision and then vote, the team accepts the choice if more than $50 \%$ of members support it, or if the majority vote for one solution.

4) By an extra expert, where nobody from the team is responsible for recognizing how useful the decision is, and to take it professionally.

It has been discovered in previous research that decision paths are influenced by two main factors: characteristics describing the executed task, and also internally its structures that define work relationships in the team (Eseryel et al., 2020). Because of the unique nature of virtual teams, it seems probable that the way of making final decisions also differs in f2f teams and $\mathrm{v}$ teams. The collaboration technology used by a virtual team can encourage users to categorize information, to judge its importance, and leads to better quality decisions (McNamara, 2008). When asynchronous communication is used, team members have much more independence in developing and testing their own solutions, before sharing them with the other members. At the same time, they are less likely to discuss all of their ideas for problem solutions (Eseryel et al., 2020). The virtual collaboration process structure, supported by a communication channel, leads to equal information voicing in the team, which stimulates the negotiation process and focuses on analyzed alternatives rather than on personal preferences (Cordes, 2016). Because virtual team member commitment and team cohesion are important challenges, the consensus decision model is fully recommended (Falkowski and Troutman, 2005). In the next part of the paper we will concentrate on the representative type of task under consideration.

Does it mean the decision-making methods are different in virtual and f2f teams? Answering the above question was the main goal of the research presented in the next part of the paper. Additionally, IT specialists' attitudes towards cloud computing were examined. In other words, we concentrate on the recognition of how IT teams make decisions about the choice of cloud computing environments, and what kind of application design and implementation methodologies are more preferable for them.

\section{THE SCOPE OF DECISION-MAKING ANALYSIS}

As has been shown, decision-making is a very complex human activity, despite the possibilities to support it by means of numerous software tools. This is true even in the case of the choice of the best solution from among possible well-known solutions. The decision-maker should consider all of the pros and cons, taking into account different possible contexts or eventual circumstances. Therefore, in this paper we limit our considerations strictly to IT teams, characterizing them by means of the following attributes:

1) type of software team: traditional (f2f) and virtual ones,

2) competence of team members described by their knowledge, capabilities and experiences,

3) kinds of solved problems: team and task-oriented ones,

4) ways of decision-making: by leader, looking for compromise, by voting or external experts. 
The difference between f2f and $\mathrm{v}$ teams comes down first of all to the communication tools used by them. Therefore it is easy to classify the type of teams being analyzed. However, the evaluation of the competence of team members is much more difficult to prepare. Competence assessment may include many factors, such as: members' experience, knowledge, attitudes, preferences, professional background, age, psychological characteristics and others. In order to limit the influence of all these variables on the results, in the research we focused on teams whose members have similar competences, as described in the next section.

As explained in Section 1, we assume that IT teams may encounter two kinds of problems to be solved:

1) team oriented problems which refer to some psychological aspects such as: low motivation level, unproductive communication, personal conflicts, or ineffective team leadership,

2) task oriented problems which focus on some technical aspects such as: team preferable technology, selection of sufficient resources, or choice of the best development methodology, and computing environment.

There are some relations between the kinds of solved problems and ways of decision-making in IT teams. However, we decided to only concentrate on some task oriented problems, but still such relations are not obvious, and they require taking into account the filter decision-making model shown in Figure 4. We decide to consider two categories of such problems as shown in Figure 5. According to the knowledge presented in Section 1 (see Fig. 2), one category refers to application design activities (Planning \& Design stage), the second one to the choice of a suitable computing environment (Implementation \& Improvement stage). For each category, as previously assumed, we define four ways of decision-making.

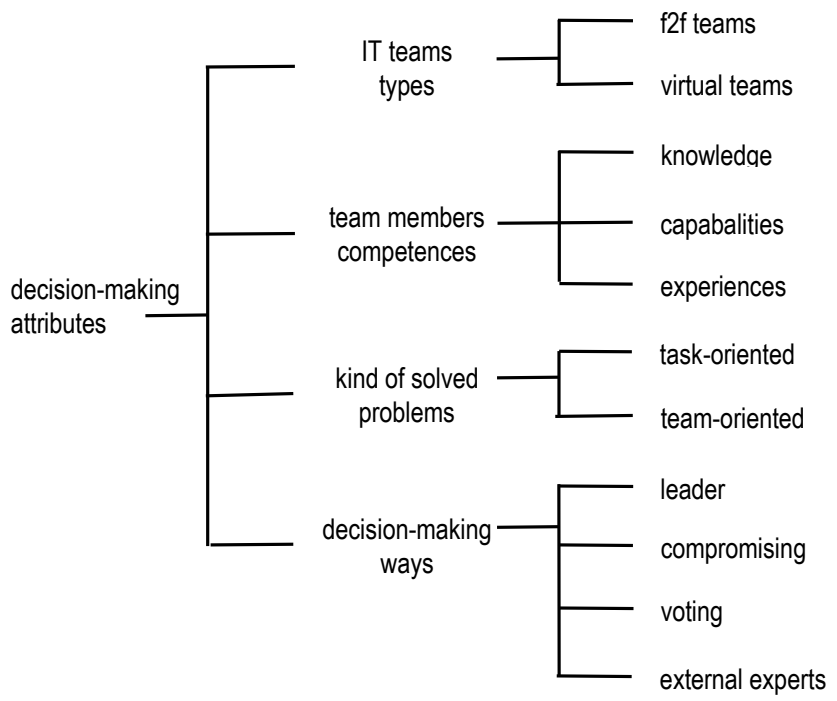

Fig. 5. The assumed attributes of IT teams influencing decision-making 
Each decision posed for IT teams can be taken in different ways: by the leader of that team, or by looking for compromise among the members of that team, by the voting of all team members, or by external experts. For representative sets of f2f and $\mathrm{v}$ teams we examine the ways of decision-making for all eight cases shown in Figure 6 . As a result, we analyzed 16 cases for each category of the considered tasks ( 4 different ways of decision-making $\times 4$ different types of task oriented problems - see Figures 5 and 6 respectively) in nearly 50 carefully selected teams. In each software team there was at least one member who was a Polish IT specialist. The majority of the teams operate in different IT companies that located in Poland, but they are not necessarily Polish organizations. The companies differ in size (the number of SME members) and have various business profiles (different final users of the designed products), but all of them are focused on designing and implementing modern application software. The obtained results are shown and discussed in the next section.

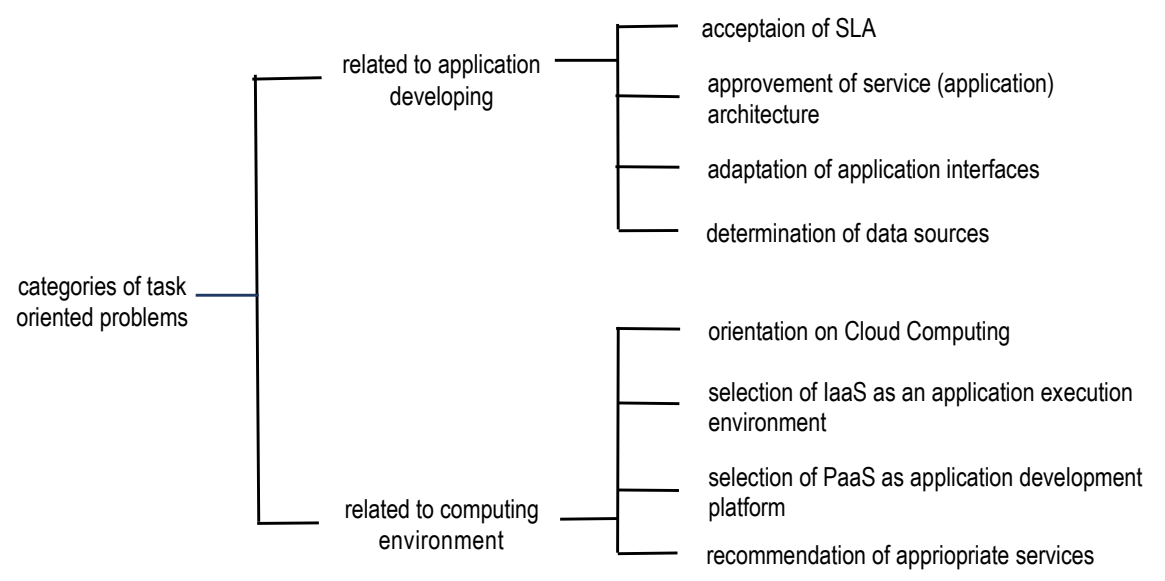

Fig. 6. The list of the chosen task oriented problems

\section{MAIN RESULTS}

In order to illustrate how decisions are made in traditional and virtual teams, a special questionnaire was distributed amongst a group of IT specialists satisfying the requirements described in Section 3. More than $50 \%$ of them decided to answer the request. Based on the surveys, we selected teams consisting of young members, as shown in Table 1, since their IT competence was nearly the same and meaning that they have almost identical amounts of knowledge, capabilities and experience about modern information technologies.

Table 1. Age of respondents

\begin{tabular}{|c|c|c|c|}
\hline Age & $18-24$ & $25-34$ & $35-44$ \\
\hline Percentage & $17 \%$ & $74 \%$ & $9 \%$ \\
\hline
\end{tabular}


Most of them are men: (89\%), and $55 \%$ of respondents have experience in virtual collaboration. Respondents were asked to point out the kind of methods they use while working in software projects and about $65 \%$ of these IT specialists were matched with agile solutions (the traditional waterfall method was indicated by $24 \%$ ). The answers to the question about which development and computing platforms are more favorable, were much more diverse (see Fig. 7).

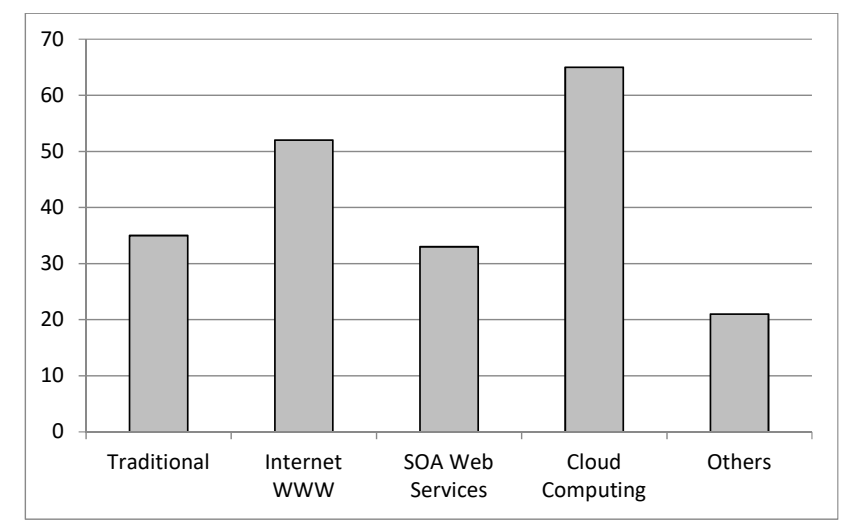

Fig. 7. Experience of respondents in use of different computing environments [\%]

However, we can assume that the selected teams satisfy our assumptions made in Section 2. More than $45 \%$ of the tested IT specialists use computing clouds in their professional tasks, and $77 \%$ of them would use cloud computing in realized projects if it were possible. Nearly $80 \%$ of respondents have preferences towards cloud computing usage, depending on their previous experiences.

It can be assumed that IT specialists' attitudes towards cloud computing are positive, since most of them use them, or would like to. Previous experiences in cloud computing raise the preference to use it in future projects. Respondents were also asked about the reasons for their acceptance or rejection of cloud computing solutions. Pros and cons were categorized into a number of groups that are presented in Table 2 .

Table 2. Pros and cons of cloud computing utilization

\begin{tabular}{|c|c|}
\hline Pros & Cons \\
\hline Calculation speed & No need to use \\
\hline Scalability & Security issues \\
\hline Software expense elimination & Loss of control \\
\hline Security & Knowledge gap \\
\hline Convenience & - \\
\hline
\end{tabular}

The most often-mentioned arguments against cloud computing were the lack of need, and security issues. IT specialists (who are against) do not trust clouds, and were 
also afraid of losing control over programming code. An interesting argument was the knowledge gap - respondents said they do not have enough information to choose or access cloud computing solutions. The pro part was dominated by time and scalability arguments. There were also some reasons based on clouds accessibility and the comfort connected with cloud computing solutions from the programmers' point of view.

The next two figures show in what way decisions are taken by IT teams in the case of task-oriented problems. As it was assumed, respondents could point to one of four ways of decision-making. Figure 8 presents differences in decision-making in the case of an application development (Planning \& Design stage). Respondents were asked to choose a favorite way of choosing a source for data application interfaces SLA's and services, while working as traditional (f2f) and v teams.

a)

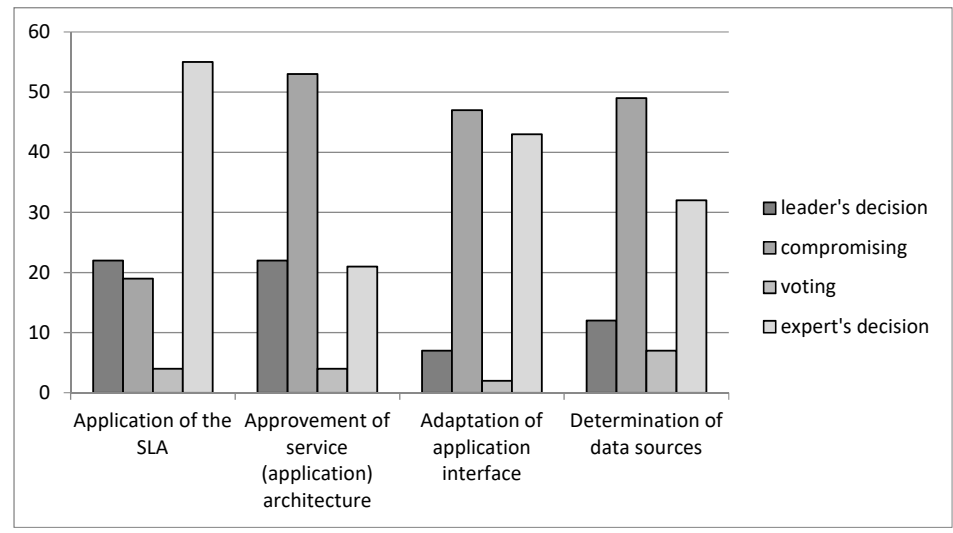

b)

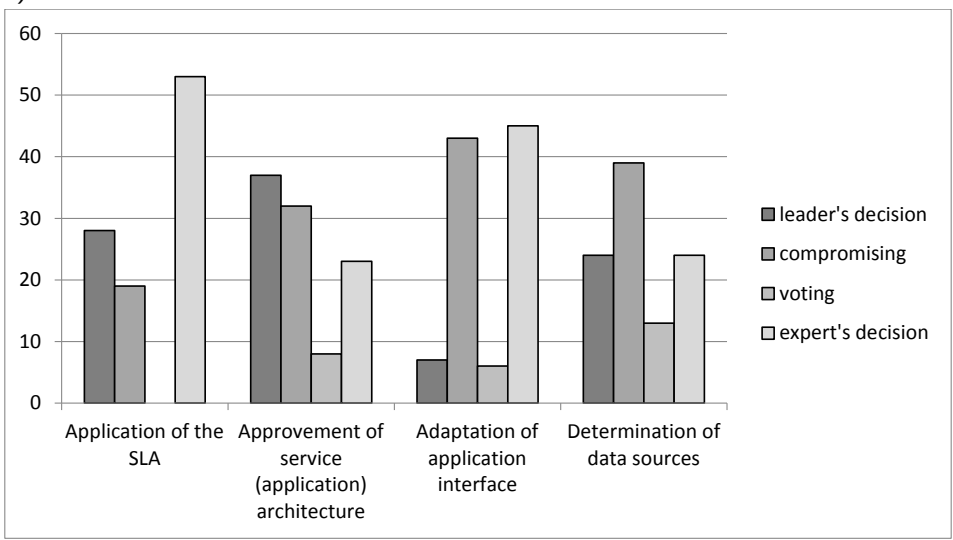

Fig. 8. Preferable ways of decision-making related to Planning $\&$ Design stage in the case of traditional (a) and virtual (b) teams 
In spite of the high experience of the teams' members, the role of an external expert in both cases is often essential. Apart from the case of the Acceptation of SLA, where the application of juridical regulations predominates, an external expert is often the decisionmaker. In other cases, the compromising method is slightly more preferable. In the case of both problems, approval of services allows the leader to take decisions, but in the case of $\mathrm{f} 2 \mathrm{f}$ teams, it is more essential to look for a compromise.

Figure 9 shows the difference in decision-making in case of Implementation \& Improvement stage.

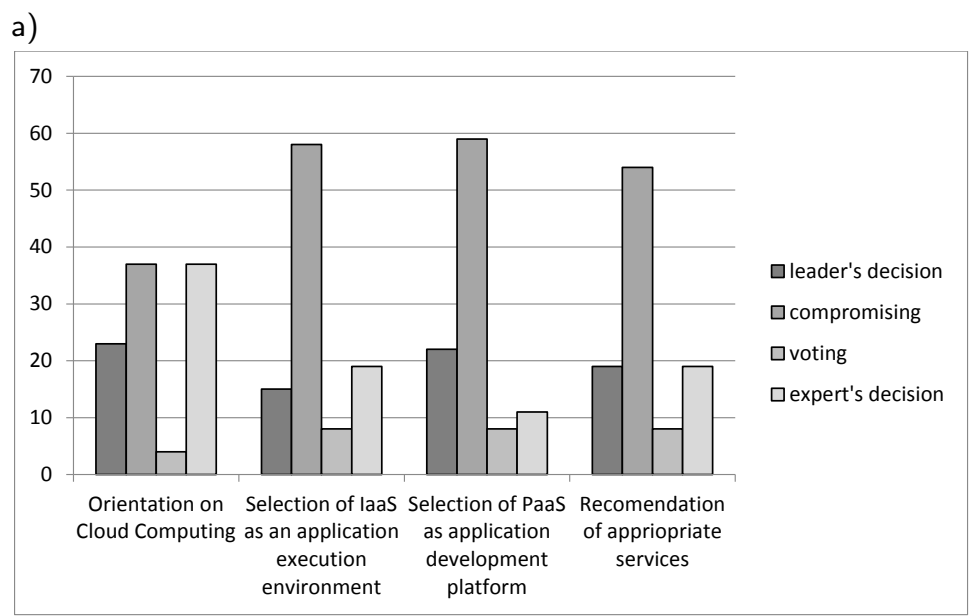

b)

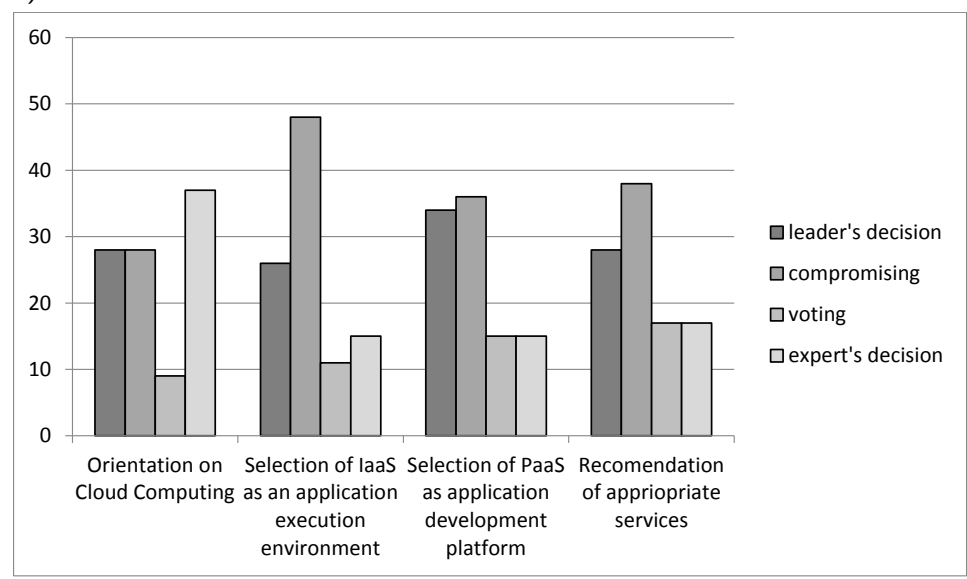

Fig. 9. Preferable ways of decision-making related to Implementation 85 Improvement stage in the case of traditional (a) and virtual (b) teams

It is clearly visible that in traditional teams the most important way of making decisions about cloud computing as a development platform was compromising. The 
leader's opinions were much more powerful in virtual teams, especially in the case of both the choice of PaaS platforms, and recommendation of appropriate services. Decisions about the choice of IaaS by $\mathrm{v}$ teams as application running environments were more often (a) Traditional teamstaken as compromising, but the role of leader seems to be stronger in the case of $\mathrm{v}$ teams than in $\mathrm{f} 2 \mathrm{f}$ teams. Moreover, voting was the least preferable way in each kind of decision-making, but it is possible to notice that this method is more frequently indicated in virtual collaboration cases.

Comparing the results referring to cloud computing usage and service choice, there are some similarities and differences. The most popular way of decision-making in $\mathrm{f} 2 \mathrm{f}$ teams was compromising, regardless of the type of task-oriented problems. In virtual teams, the leader was sometimes responsible for the decision for PaaS platform usage, and members were rather empowered to make the decision about the IaaS environment. An expert's decision is also required in some cases to answer the question of whether cloud computing should be used. Leader decisions were much more popular in the virtual team case for each category of the problems. The least popular team decision was voting, but it was slightly more prevalent in virtual teams in the case of service choice.

\section{FINAL REMARKS}

It is a well-known fact that decision-making is an important part of project process management. There are numerous factors that have a considerable influence on such a process. In this paper, some of those related to modern design and implementation environments, i.e. cloud computing, were discussed and the result of surveys related to decision-making are presented. Moreover, we considered two kinds of IT teams: traditional and virtual ones, in order to analyze the most popular ways of decision-making in the case of application development problems or the selection of execution environments. The achieved results are as follows:

1) In traditional teams, members seek compromising solutions. It seems that direct personal contact determine such approaches.

2) The virtual environment, which is believed to be a boon for self-managed teams of experts, stimulates teams to rely more on compromising opinions than on the leader's suggestions; but this existing dominance it is not as high in comparison to f2f teams. This may be the result of low trust and low cohesion in $\mathrm{v}$ teams (especially in Polish conditions). As a result, different ways of building trust and commitment should be implemented in these kinds of teams in order to promote team discussions and information sharing.

3) Voting is fortunately perceived as the worst way of decision-making. It is important in the case of the development of different services supporting virtual team decisions. The disadvantages of this way of making decisions, such as: possible team division, lack of satisfaction and commitment in the losers' group, should be better understood and eliminated.

4) The influence of team virtualization on results obtained in cloud computing environments needs to be more deeply analyzed. It should be confirmed that software teams make better decisions, and make their collaboration more effective, thanks to cloud computing. 
The obtained results provide only preliminary knowledge, and further research is necessary. Other aspects of software team characteristics, such as higher diversity of the teams, or more complex decision-oriented problems, as well as the impact of technologies, can be taken into account. IT specialist attitudes towards cloud computing were briefly analyzed, and based on the present research, cloud computing seems to be widely accepted in many research groups. One of the reasons for negative attitudes can be the existing knowledge gap, which is astonishing in a group of IT specialists. This suggests the need for the promotion of the pros and cons of cloud computing in such groups, because the lists generated by respondents do not cover those given by cloud computing experts. It emphasizes that there is also a need to improve education in the area of cloud computing.

\section{REFERENCES}

Bourgault, M., Dronin, N., Homel, E., 2008. Decision-making with distributed project teams: an exploration of formalization and autonomy as determinants. Project Management Journal, 39(3), pp. 9-110.

Cohen, B., 2013. PaaS: New Opportunities for cloud Application Development. IEEE Computer, 46(9), pp. 9-100.

Cordes, S., 2016. Virtual team learning: The role of collaboration process and technology affordance in team decision making. Knowledge Management \& E-Learning, 8(4), pp. 602-627.

Dávideková, M., Hvorecký, J., 2017. ICT Collaboration Tools for Virtual Teams in Terms of the SECI Model. International Journal of Engineering Pedagogy, 7(1), pp. 95-116.

Eseryel, Y., Wei, K., \& Crowston, K., 2020 Decision-making processes in community-based Free/libre Open Source Software development teams with internal governance: An extension to decision-making theory. Communication of the AIS (CAIS) (in press).

Falkowski, G., Troutman, S., 2005. Remote Control: A Practitioner's Guide to Managing Virtual Teams. An IHRIM Press Book, USA.

McNamara, K., Dennis, A.R., Cart, T.A., 2008. It's the Thought that Counts: The Mediating Effects of Information Processing in Virtual Team Decision Making. Information Systems Management, 25(1), pp. 20-32.

Nemiro, J., Beyerlein, M., Bradley, L., Beyerlein, S. (eds.) 2008. The Handbook of High Performance Virtual Teams. John Wiley \& Sons.

Phillips, J., 2004. IT Project Management. On Track from start to Finish 2e. The McGraw-Hill Companies.

Pollice, P., Augustine, L., Lowe, Ch., Madhur, J., 2004. Software Development for Small Teams: A RUP-Centric Approach. The Addison-Wesley Object Technology Series. Pearson Education, Inc.

Schmidt, J.B., 2001. New Product Development Decision-Making Effectiveness: Comparing Individuals, Face-To-Face Teams, and Virtual Teams. Decision Sciences, 32(4), pp. $575-600$.

Shalloway, A., Beaver, G., Trott, J.R., 2009. Lean-Agile Software Development. Achieving Enterprise Agility. Addison-Wesley Professional. Pearson Education, Inc. 
Turban, E., Liang, T., Wu, S.P.J., 2011. A Framework for Adopting Collaboration 2.0 Tools for Virtual Group Decision Making. Group Decision Making, 20, pp. 137-154.

Vasan, R., 2011. A Venture Perspective on Cloud Computing. IEEE Computer, 44(3), pp. 60-62.

Zofi, Y., 2012. A Manager's Guide to Virtual Teams. Amacom, USA. 